\title{
In situ ingestion rates of appendicularian tunicates in the Northeast Water Polynya (NE Greenland)
}

\author{
José Luis Acuña*, Don Deibel, A. B. Bochdansky, E. Hatfield \\ Ocean Sciences Centre, Memorial University of Newfoundland, St. John's, Newfoundland A1C 5S7, Canada
}

\begin{abstract}
We report in situ ingestion rates of individual oikopleurid appendicularians from the Northeast Water Polynya (NEW) determined by a modification of the gut pigment technique. Appendicularians were most abundant at ice edge stations and were rare at open water stations in the centre of the polynya. Gut passage time (GPT), which was determined in experiments onboard ship, was not related to body size (mean $\pm \mathrm{SD}=74 \pm 23 \mathrm{~min}$ ). Gut chlorophyll content (GCC) excluding phaeopigments (i.e. GCC = chlorophyll $a+b+c$ ), averaged $4.06 \mathrm{ng}$ ind.$^{-1}$, with quartiles of 1.20 to $4.73 \mathrm{ng}$ ind.$^{-1}$. There was no evidence of a diel feeding rhythm. GCC was higher and more variable at non-bloom (i.e. at chlorophyll concentrations $<0.8 \mathrm{mg} \mathrm{m}^{-3}$ ) than at bloom stations, and was inversely related to the relative proportion of chlorophyll in particles $>5 \mu \mathrm{m}$ in size. This suggests inhibition of ingestion rates at ice edge stations with diatom blooms. The ingestion rate (IR, ng chlorophyll ind ${ }^{-1} \mathrm{~d}^{-1}$ ) of individual appendicularians in the NEW can be predicted by $I R=2.5 \mathrm{BL}: \mathrm{BT}^{-041} \mathrm{TL}^{2.14}\left(\mathrm{r}^{2}=0.43\right)$ where $\mathrm{BL}: \mathrm{BT}$ is the ratio of chlorophyll $a$ in particles $>5 \mu \mathrm{m}$ in diameter to the total chlorophyll biomass, and TL (mm) is the trunk length.
\end{abstract}

KEY WORDS: Zooplankton · Appendicularian · Feeding · Polynya $\cdot$ Gut pigments

\section{INTRODUCTION}

Polynyas are mesoscale ice-free areas in the midst of ice-covered seas that serve as important foraging areas for large animals, including birds, seals, walruses, whales and man (Stirling 1980). Polynyas are created and maintained by physical factors such as winds, tides, upwelling or regional currents (Smith et al. 1990, Schneider \& Budéus 1995). During spring and summer 1993, an international, multidisciplinary expedition to the Northeast Water Polynya (NEW) tested the hypothesis that opening of the polynya leads to the formation of a short food chain based upon diatom production while the under-ice food web is a complex microbial loop based upon very small producers (e.g. bacteria). Because 2 oikopleurid appendicularians, Oikopleura vanhoeffeni and $O$. labradoriensis, are particularly abundant in subarctic and arctic waters (Udvardy

\footnotetext{
- Present address: Laboratorio de Ecología, Departamento de Biología de Organismos y Sistemas, Facultad de Biología, Universidad de Oviedo, C/ Catedrático Rodrigo Uría (S/N), Oviedo 33071, Spain. E-mail: acuna@sci.cpd.uniovi.es
}

1954, Grainger 1965, Buchanan \& Browne 1981), and because appendicularian populations frequently have a particle removal capacity equivalent to that of all of the copepod species in the community combined (Knoechel \& Steel-Flynn 1989, Buck \& Newton 1995), we were interested in quantifying the individual and population ingestion rates of these animals in the NEW.

Appendicularians use a system of external and internal mucous filters to remove particles from seawater suspension. Gut contents and particle size retention efficiencies indicate that appendicularians retain a broad size range of particles, from submicrometre colloids to large diatoms (Deibel \& Turner 1985, Deibel \& Lee 1992, Urban et al. 1992, 1993). In previous studies of appendicularian ingestion, investigators have used proxy food, including latex spheres (Alldredge 1981, Deibel 1988) and radio-labeled algae (Knoechel \& Steel-Flynn 1989). The gut pigment technique, based on determining the quantity of phytoplankton pigments in the gut and the turnover rate of gut contents during short experiments, is an alternative to artificial marker particles for determining in situ ingestion rates 


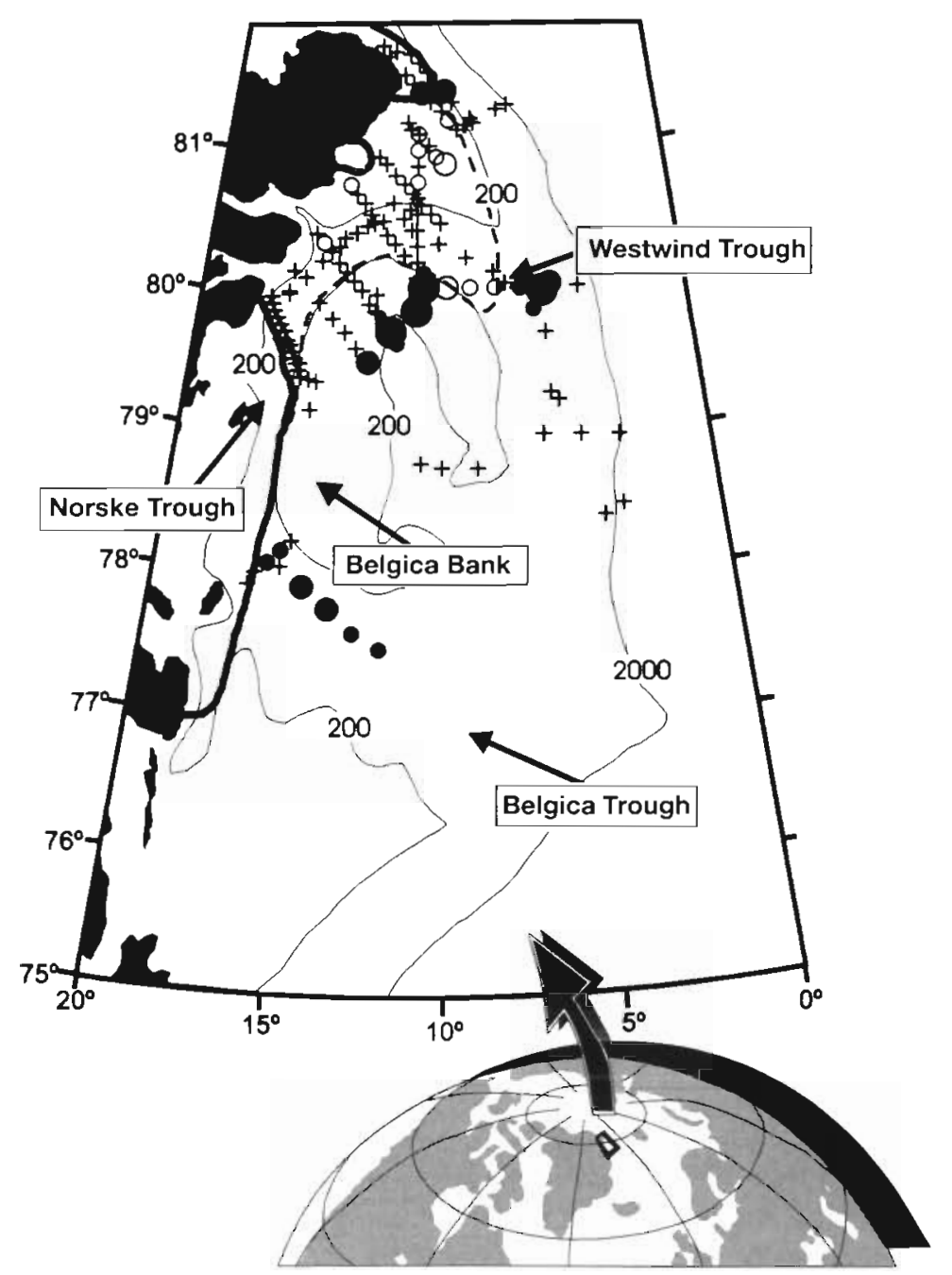

Fig. 1. Map of the study area of RV 'Polarstern' cruise ARK IX/3 showing the location of stations at which appendicularians were sampled for gut pigment analysis $(0,0)$ and those at which appendicularians were essentially absent (+). (O) Bloom stations at which the vertically averaged chlorophyll concentration (over the upper $50 \mathrm{~m}$ ) was higher than $0.8 \mathrm{mg}$ $\mathrm{m}^{-3}$, and (1) non-bloom stations at which the vertically averaged chlorophyll concentration was less than $0.8 \mathrm{mg} \mathrm{m}^{-3}$ The 3 different sizes of circles indicate the value of the gut pigment index $10^{1}\left(\mathrm{ng} \mathrm{chl} \mathrm{ind}{ }^{-1}\right)$ for each station. $10^{i}$ is the normalized gut chlorophyll content (GCC) of a standard appendicularian $1 \mathrm{~mm}$ long. Small circles represent $10^{i}<1 \mathrm{ng}$ ind. ${ }^{-1}$, medium circles $1<10^{\prime}<2 \mathrm{ng}$ ind. ${ }^{-1}$, and large circles $10^{\prime}>2 \mathrm{ng}^{\prime} \mathrm{ind}^{-1}$. (- - -) Outer limit of open water (i.e. the open polynya water was located between this line and the coast) on 27 July 1993, during a time of maximum opening of the polynya (adapted from Pesant et al. 1996).

Edges of the landfast ice of the Ob Bank Ice Barrier (northernmost), and the Norske Øer Ice Barrier (southernmost)

of autotrophic food by pelagic tunicates (Madin \& Kremer 1995). Rapid sample collection and analysis using this technique allows for large-scale mapping of ingestion rates which is not possible using other time-consuming approaches, which explains why the gut pigment technique has been used with salps (Madin \&
Cetta 1984, Madin \& Purcell 1992, Madin \& Kremer 1995) and copepods (Head 1986). To date, only 2 studies have considered in situ feeding by appendicularians determined using gut fluorescence information (Jansa 1977, Landry et al. 1994a,b). However, neither of these studies included the determination of gut passage time, so the derivation of ingestion rates was not possible.

Here we report individual ingestion rates of the predominant oikopleurid appendicularians in the NEW as measured by a modification of the gut pigment technique, including development of new methods to sample, maintain and conduct experiments on living appendicularians onboard ship. We aimed at describing the variability of ingestion rates of appendicularians in the NEW over large space and time scales (10s to several hundred $\mathrm{km}$ over $6 \mathrm{wk}$ ), and at determining the most likely physical and biological factors accounting for this variability.

\section{METHODS}

We report data collected during $\mathrm{RV}$ 'Polarstern' cruise ARK IX/3 to the NEW, between 25 June and 4 August 1993 (Fig. 1). Methods for collecting temperature, salinity and in situ fluorescence data are given in Hirche \& Kattner (1994) and Budéus \& Schneider (1995) and for collecting ice cover information in Hirche \& Kattner (1994) and Pesant et al. (1996). Total phytoplankton pigments (i.e. the sum of chlorophyll and a-type phaeopigments) were determined on 2 size fractions $(0.45$ to $5 \mu \mathrm{m}$, and $>5 \mu \mathrm{m})$ using a Turner 112 fluorometer fitted with a standard, broad-band filter set (Pesant et al. 1996). Phaeopigments were subtracted from total pigments to arrive at undegraded chlorophyll values, making the measurements of available phytoplankton pigments comparable to our measurements of gut chlorophyll content (see below).

Gut chlorophyll content (GCC). Appendicularians for gut chlorophyll analyses were collected using vertical hauls of a Bongo net frame with a $50 \mathrm{~cm}$ mouth opening, fitted with a net made of $200 \mu \mathrm{m}$ mesh. The net was retrieved from $200 \mathrm{~m}$ depth to the surface at a velocity of ca $1 \mathrm{~m} \mathrm{~s}^{-1}$. Periodic, vertically stratified tows indicated that most of the appendicularians were living within $50 \mathrm{~m}$ of the surface (Ashjian et al. 1995, 1997. Hirche et al. un- 
publ.). Immediately after arrival on deck, the cod end contents were diluted with filtered seawater (Whatman GF/F filters) collected from ca $7 \mathrm{~m}$ depth. The diluted sample was taken quickly to a $0^{\circ} \mathrm{C}$ container laboratory below deck. Following removal of sub-samples for taxonomy (4\% formaldehyde-seawater), appendicularians were removed one-at-a-time from the dilute cod end contents using a glass pipette. Each appendicularian was rinsed 3 times with filtered seawater, and deposited onto a glass well slide. After 5 to 18 individuals had been collected on slides depending on the station, each was identified and measured to the nearest $0.02 \mathrm{~mm}$ under red light using a Zeiss dissecting microscope. Our measurement of trunk length was defined as the distance between the mouth and the posterior edge of the stomach, not taking into account the gonads (Shiga 1976).

We did not sort the appendicularians by species. The 2 oikopleurid appendicularians known from the arctic are Oikopleura vanhoeffeni and $O$. labradoriensis, which are very similar and can only be distinguished from one another when alive. Because of time demands of the gut pigment work, we were not able to look through live samples onboard, although preliminary inspection in the NEW showed that ca $90 \%$ were $O$. vanhoeffeni, which is similar to the relative abundance of these 2 species in Newfoundland waters.

Next, the number of faecal pellets was recorded both within the gut of the animal and deposited in the well plate. The house rudiment (if present) was removed by dragging the upper part of the trunk against the glass surface of the slide. The tail was then cut off with a dissecting blade because of its potential confounding effect on pigment analysis due to high concentrations of beta-carotene, astaxanthin and asteraxanthin (Deibel \& Head unpubl.). Next, the trunk and any faecal pellets released into the well slide were transferred to a $1.5 \mathrm{ml}$ Eppendorf tube which was flash frozen in liquid nitrogen and stored in the dark at $-20^{\circ} \mathrm{C}$ until analysis onshore. The above procedure took up to $40 \mathrm{~min}$ at stations where appendicularians were abundant.

After the cruise, the samples were shipped via airfreight to our home laboratory in Newfoundland in a $20 \mathrm{l}$ cooler filled with dry ice. Total chlorophyll (i.e. chlorophyll [chl] $a+b+c$ ) was determined using a Sequoia-Turner model 450 digital fluorometer equipped with a narrow band excitation filter (NB 440) and a sharp-cut emission filter (SC 665). The instrument was calibrated using a pure chl a standard (Sigma Chemicals). This filter set is designed to exclude all a-type phaeopigments from the signal, thus avoiding the inaccuracies of phaeopigment determination using a conventional broad-band filter and the traditional acid-ratio equations in the presence of chl $b$ and $c$
(Bochdansky et al. 1998). This modification of the gut pigment technique was possible because we have found that appendicularians convert a predictable proportion $($ mean $=79 \%$ with $95 \% \mathrm{CL}$ of 76 to $83 \%$ ) of ingested chlorophyll to phaeopigments and colorless products (Bochdansky et al. 1998). Also, the SequoiaTurner 450 fluorometer has sufficient sensitivity to make relatively rapid determinations of GCC of single individuals with near-HPLC specificity for total chlorophyil (Bochdansky et al. 1998). This permits the analysis of large numbers of samples in a fraction of the time required for HPLC work, making large-scale mapping of ingestion rates possible, an initial strength of the gut pigment technique (Mackas \& Bohrer 1976) which has been lost with the increasing reliance on timeconsuming and costly HPLC analyses.

To analyze the GCC of each appendicularian, $1.25 \mathrm{ml}$ of chilled acetone was added to each Eppendorf tube, which was then sonicated for $3 \mathrm{~min}$ in a water bath filled with crushed ice. Pigments were extracted at $-20^{\circ} \mathrm{C}$ for $24 \mathrm{~h}$. Each tube was then sonicated and centrifugued at $9500 \mathrm{RCF}$ (relative centrifugal force) for 3 minutes at room temperature. After 10 more minutes in the dark at room temperature, total chlorophyll fluorescence (i.e. chl $a+b+c$ ) of each sample was analyzed by retrieving $1 \mathrm{ml}$ of the supernatant and pipetting it into a cuvette, which was then diluted to $1.5 \mathrm{ml}$ by adding $0.5 \mathrm{ml}$ of $90 \%$ acetone. The fluorescence of the sample was then determined without acidification (i.e. relative fluorescence units) using a SequoiaTurner 450 fluorometer (see above).

Appendicularians for determination of background fluorescence were collected at Logy Bay, insular Newfoundland, in Winter 1994. The same species occur at the same water temperatures in Logy Bay and in the NEW (i.e. Oikopleura vanhoeffeni and O. labradoriensis). Appendicularians were starved for $5 \mathrm{~h}$, which is sufficient time for the gut to empty ca 5 times (Bochdansky et al. 1998). Following this depuration interval, the appendicularians were collected and processed for GCC as above. There was a significant allometric relationship between background $\mathrm{GCC}\left(\mathrm{GCC}^{*}\right.$, ng ind. ${ }^{-1}$ ) and trunk length (TL, mm): $\mathrm{GCC}^{\cdot}=0.022 \mathrm{TL}^{2.81}(\mathrm{n}=5$, $\mathrm{r}^{2}=0.97, F=109, \mathrm{p}<0.01, \mathrm{SE}$ of the slope $=0.27, \mathrm{SE}$ of the intercept $=1.38$ ). The size range of animals sampled for blank readings was from 2.1 to $4.4 \mathrm{~mm}$, covering $53 \%$ of the size range of animals sampled in the NEW (from 0.55 to $3.88 \mathrm{~mm}$, see 'Results'). We have assumed that the allometric relationship for blank readings extends linearly to small appendicularian sizes.

Gut passage time (GPT) and faecal pellet production rate. Appendicularians for GPT experiments were collected with a large cod end plankton net (Reeve 1981), made of $110 \mu \mathrm{m}$ mesh, with a mouth diameter of $1 \mathrm{~m}$ and a $45 \mathrm{l}$ acrylic cod end. The net was retrieved at ca $30 \mathrm{~m}$ 


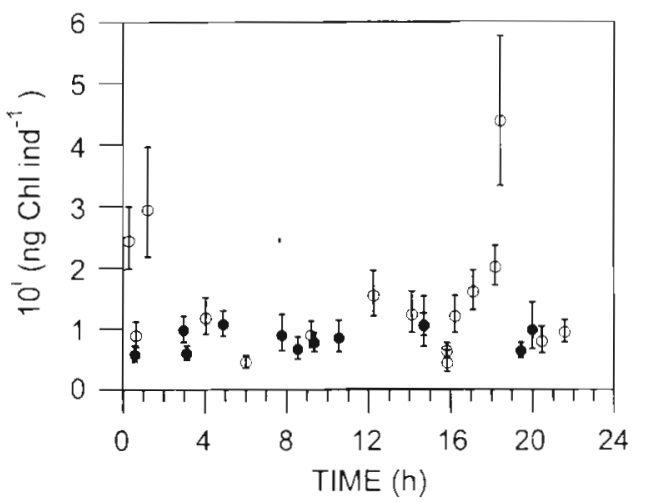

Fig. 3. Diel patterns in body-size-normalized gut chlorophyll content $\left(10^{i}\right)$ versus time of the day for all NEW stations sampled for GCC. $(0, \bullet)$ Stations where chlorophyll concentration was $<0.8$ and $>0.8 \mathrm{mg} \mathrm{chl} \mathrm{m^{-3 }}$ respectively. There were no significant differences in $10^{\prime}$ among six 4 h intervals for all stations pooled (Kruskal-Wallis analysis by sanks, $\mathrm{n}=28, H=$ 2.95, $\mathrm{p}=0.707$ ), only for stations with average chlorophyll concentration $<0.8 \mathrm{mg} \mathrm{m}^{-3}(\mathrm{n}=17, H=7.29, \mathrm{p}=0.2)$, and only for stations with average chlorophyll concentration $>0.8 \mathrm{mg}$ $\mathrm{m}^{-3}(\mathrm{n}=11, H=4.85, \mathrm{p}=0.3)$. Error bars represent $10^{14} \mathrm{SE}$ and $10^{-5 E}$

accepting that the slopes were not different from one another when in fact they were different. However, an additional ANCOVA analysis of only those stations with significant within-station regressions between GCC and TL (i.e. $\mathrm{n}=15$ stations) also resulted in the conclusion that the slopes were not significantly different from one another $(p=0.33)$ with a common slope value of $2.22 \pm 0.16( \pm \mathrm{SE} ; \mathrm{n}=168$ individuals; number of stations $=15$ ). Furthermore, separate ANCOVA analyses made on diatom bloom stations (average chlorophyll concentration $>0.8 \mathrm{mg} \mathrm{m}^{-3}$ ) and non-bloom stations (average chlorophyll concentration $<0.8 \mathrm{mg}$ $\mathrm{m}^{-3}$ ) did not result in rejecting the null hypothesis of equal slopes within each group $(p=0.94$ and $p=0.21$, respectively) and gave similar slope estimates to those above.

Although station-wise slopes of the allometric regressions of $\log$ GCC versus $\log$ TL were statistically undistinguishable, there were significant differences in intercept among stations $\left(\mathrm{ANCOVA}_{i} F_{27,231}=4.87\right.$, $\mathrm{p}<0.001)$. Therefore, at each station the allometric relationship between GCC and TL was described by the equation $\log \mathrm{GCC}=2.08 \log (\mathrm{TL})+i$, where $i$ is a station-specific intercept which can be calculated following Armitage \& Berry (1987). Therefore, after reverse transformation, the allometric equation for $\mathrm{GCC}$ versus TL for each station is,

$$
\mathrm{GCC}=10^{\prime} \mathrm{TL}^{2.08}
$$

Note that, in Eq. (1), $10^{\prime}$ is equivalent to the GCC of a standard animal $1 \mathrm{~mm}$ long. In the following sections,

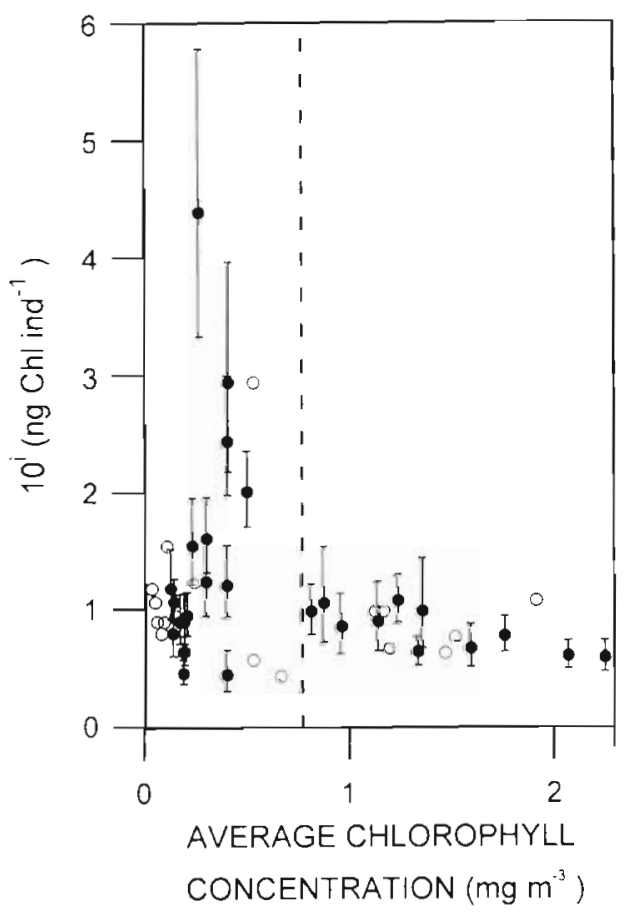

Fig. 4. Plot of the body size corrected index of gut chlorophyll content $\left(10^{\prime}\right)$ versus the average chlorophyll concentration over the upper $50 \mathrm{~m}$ of the water column, determined from in situ fluorescence ( $\bullet$ ) and from acetone extracts of sub-samples from Niskin bottles (O). Error bars represent $10^{1+S E}$ and $10^{-S E}$ The vertical dashed line separates stations with chlorophyll concentrations below and above $0.8 \mathrm{mg} \mathrm{m}^{-3}$

we will use $10^{i}$ as a body-size-corrected index of overall gut fullness for each station. Over the entire 28 stations, $10^{i}$ had a mean of $1.20 \pm 0.16 \mathrm{ng}$ ind ${ }^{-1}( \pm \mathrm{SE})$. ranging between 0.44 and $4.38 \mathrm{ng}$ ind. ${ }^{-1}$. What are the most likely environmental factors accounting for this variability of $10^{1}$ among stations? We explored this question by examing the effect of time of day and food concentration on $10^{\prime}$.

We expected $10^{i}$ to have no diel cycle and to increase with increasing ambient chlorophyll concentration. There was no apparent relationship between $10^{\prime}$ and time of day when considering all stations or when the stations where sorted by their average chlorophyll concentration (Fig. 3). Thus, our first hypothesis was supported. However, a scatter plot of $10^{i}$ versus vertically averaged chlorophyll concentration did not reveal a monotonic increase with increasing food concentration, but a complex relationship with 2 domains of points (Fig. 4). At chlorophyll concentrations below $0.8 \mathrm{mg}$ $\mathrm{m}^{-3}, 10^{i}$ was variable, with values ranging from 0.44 to $4.5 \mathrm{ng}$ ind.$^{-1}$ and 6 stations having $10^{i}>1.5 \mathrm{ng}$ ind ${ }^{-1}$. At chlorophyll concentrations above $0.8 \mathrm{mg} \mathrm{m}^{-3}, 10^{i}$ was significantly less variable, with much lower values and no stations having $10^{i}>1 \mathrm{ng} \mathrm{chl} \mathrm{ind} .^{-1}$ (Levene's test for 
homogeneity of variances $p<0.01$; Kolmogorof-Smirnov non parametric test, $Z=1.37, \mathrm{n}=28, \mathrm{p}=0.047$ ) (Fig. 4). Comparative data from extracted pigment samples also indicate higher variability of $10^{i}$ below a pigment concentration of $0.8 \mathrm{mg} \mathrm{m}^{-3}$ (open circles in Fig. 4).

Next, we asked the question of whether the relationship between GCC and ambient chlorophyll concentration was fundamentally different for appendicularians of differing body sizes. To do this, we plotted observed GCC versus ambient chlorophyll concentration for all appendicularians subdivided into 9 body size classes, from $<0.88 \mathrm{~mm}$ to $>2.63 \mathrm{~mm}$ (Fig, 5). All body size classes except the largest one had a pattern of GCC versus chlorophyll concentration essentially the same as that of $10^{i}$ versus chlorophyll concentration, indicating maximum GCC at low or intermediate food concentrations and decreasing GCC at higher food concentrations (compare Fig. 4 with Fig. 5A to I). The largest individuals $>2.63 \mathrm{~mm}$ long were the only ones having maximum GCCs at food concentrations above $0.8 \mathrm{mg} \mathrm{m}^{-3}$ (Fig. 5I), indicating some ability to ingest the larger cells responsible for the higher chlorophyll concentrations. Thus, our hypothesis of monotonically increasing GCC with increasing chlorophyll concentration was rejected for all body size classes except the largest.

The simplest explanation for the inverse relationship between $10^{i}$ and chlorophyll concentration (Fig. 4) is that the inlet filters of the house are clogged by the large diatom cells responsible for the high chlorophyll concentrations (see 'Discussion'). From this hypothesis we would predict that when the relative abundance of large phytoplankton is high, GCC should be low, regardless of the concentration of smaller, ingestible particles. Next, we tested this prediction.

$10^{i}$ was significantly correlated with 2 environmental descriptors, average temperature and the ratio of the abundance of large $(>5 \mu \mathrm{m})$ to total phytoplankton (i.e. the ratio $\mathrm{BL}: \mathrm{BT}$ ) (Table 2 ). The relationship between $10^{i}$ and BL:BT was the stronger of the 2 correlations. Furthermore, as BL:BT increased, the value of $10^{1}$ decreased, in accordance with our prediction of an inverse relationship of $10^{i}$ with the relative abundance of large particles.

An appealing characteristic of the index BL:BT is that it has been used by Pesant et al. (1996) as a metric to divide the NEW into several biogeographic provinces, including Zones 1 and 2, dominated by blooms of large diatoms, and Zone 5, dominated by cells $<5 \mu \mathrm{m}$ in diameter. Thus, we used BL:BT to build a regression equation to predict GCC of oikopleurid appendicularians in the NEW Our multiple linear regression model included $\log$ TL and $\log$ (BL:BT) as independent variables and $\log (\mathrm{GCC})$ as the depen-

Table 2. Correlation of the body-size-corrected gut chlorophyll content (GCC, 10') with environmental co-variables. Because $10^{i}$ was not normally distributed, we have used the non-parametric correlation statistic, Kendall's Tau. BT: total chlorophyll in bottle extracts, BS: $<5 \mu \mathrm{m}$ and BL: $>5 \mu \mathrm{m}$ chlorophyll in bottle extracts. By far the strongest correlation was with the index of phytoplankton size composition BL:BT (inverse correlation). ns: not significant

\begin{tabular}{|lrcc|}
\hline Co-variable & Tau & $\mathrm{p}$ & $\mathrm{n}$ \\
\hline Mean temperature & -0.26 & $<0.05$ & 28 \\
Mean salinity & 0.22 & $\mathrm{NS}$ & 28 \\
Ice cover & 0.08 & $\mathrm{NS}$ & 23 \\
Mean in situ chlorophyll & -0.17 & $\mathrm{NS}$ & 28 \\
BT & -0.18 & $\mathrm{NS}$ & 18 \\
BS & 0.10 & $\mathrm{NS}$ & 18 \\
BL & -0.18 & $\mathrm{NS}$ & 18 \\
BL:BT & -0.73 & $<0.05$ & 18 \\
\hline
\end{tabular}




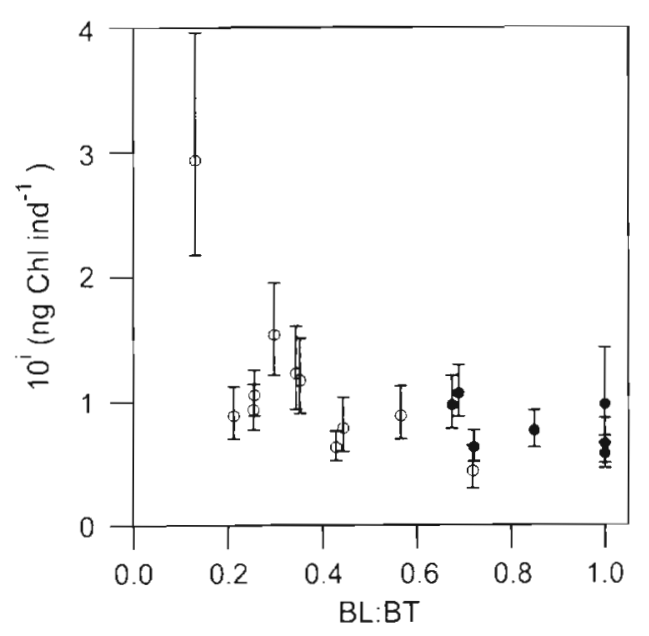

Fig. 6. Plot of the body-size-corrected index of gut chlorophyll content $\left(\mathrm{GCC}, 10^{i}\right.$ ) versus the ratio of chlorophyll concentration in particles $>5 \mu \mathrm{m}$ in diameter to the concentration of total chlorophyll (BL:BT). (o) Non-bloom stations (chlorophyll concentration $<0.8 \mathrm{mg} \mathrm{m}^{-3}$ ) and ( ) bloom stations (chlorophyll concentration $>0.8 \mathrm{mg} \mathrm{m}^{-3}$ ). Error bars represent $10^{1+\mathrm{SE}}$ and $10^{i-S E}$. The point with the lowest $B L: B T$ and the highest $10^{i}$ corresponds to a group of stations showing high $10^{\prime}$ (up to $4.38 \mathrm{ng} \mathrm{chl} \mathrm{ind.}{ }^{-1}$ ) and located at the northernmost part of the Belgica Bank (see Fig. 1)

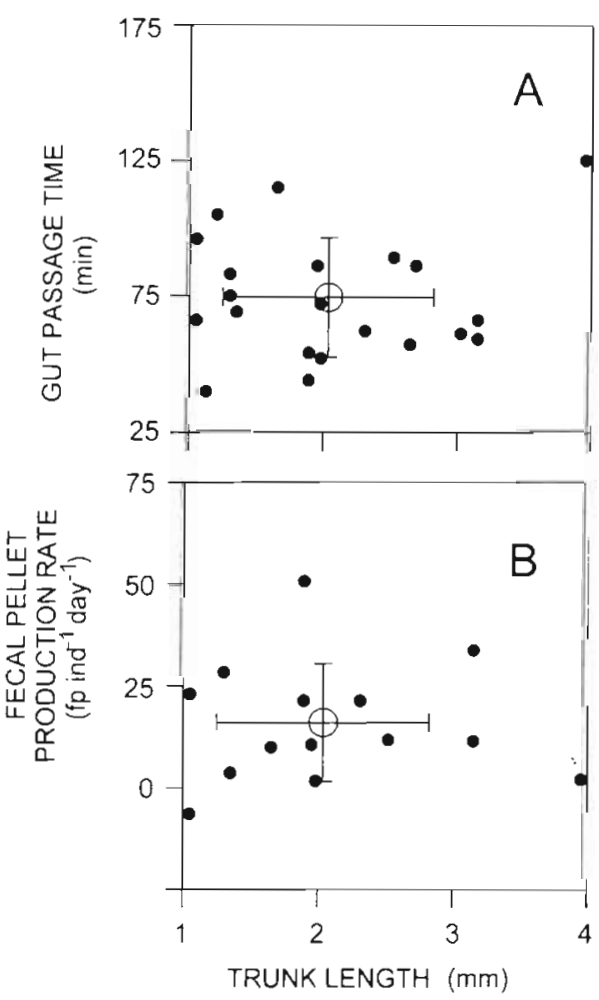

Fig. 7. (A) Plot of gut passage time versus trunk length. (O) Means and (-) standard deviations. (B) Plòt of fecal pellet production rate versus trunk length. Symbols as in (A) dent variable (TL in $\mathrm{mm}_{i} \mathrm{BL}$ :BT has no units). Log transformation was used to account for the allometric relationship between GCC and TL (Fig. 2) and the non-linear relationship between $\mathrm{GCC}$ and $\mathrm{BL}: \mathrm{BT}$ (Fig. 6). The resulting equation is

$$
\begin{aligned}
\log (\mathrm{GCC})= & (-0.19 \pm 0.07)+(-0.41 \pm 0.11) \log (\mathrm{BL}: \mathrm{BT}) \\
& +(2.14 \pm 0.19) \log (\mathrm{TL})
\end{aligned}
$$

All 3 regression coefficients were significantly different from 0 ( $t$-statistic for testing $\mathrm{H}_{0}$ : coefficient $=0$ was $t=-2.8, \mathrm{p}=0.006$ for the intercept, $t=-3.7, \mathrm{p}<0.001$ for the slope of $\log (\mathrm{BL}: \mathrm{BT})$ and $t=11.3, p<0.001$ for the slope of log (TL)). The percentage of explained variance was $43 \%$, with $\mathrm{n}=173$ and $F=64$. When back-transformed, equation 2 becomes

$$
\mathrm{GCC}=0.65 \mathrm{BL}: \mathrm{BT}^{-0.41} \mathrm{TL}^{2.14}
$$

Note that this equation is consistent with the variance structure as depicted by ANCOVA analysis (Eq. 1). GCC is related to TL by an allometric function with an exponent of 2.14, very close to our estimate of a common slope of 2.08 . The term $10^{i}$ in Eq. (1), or GCC of a standard appendicularian measuring $1 \mathrm{~mm}$, is given in Eq. (3) by $0.65 \mathrm{BL}: \mathrm{BT}^{-0.41}$. In fact, when Eq. (3) is solved for $\mathrm{TL}=1$, it nicely describes the trend of $10^{i}$ versus BL:BT in Fig. 6 (graph not shown). Eq. (3) is robust, spanning stations with almost no diatoms (i.e. BL:BT < 0.2, Pesant's Zone 5), to stations with almost pure diatom blooms (i.e. BL:BT 1.0, Pesant's Zone 1). It is also a simple equation with biologically meaningful parameters which can be used to estimate the GCC of appendicularians in the NEW based on body size and the relative abundance of large phytoplankton. It can be applied to the goal of estimating the ingestion rate of appendicularians at any station in the NEW (see below).

\section{Gut passage time (GPT) and ingestion rates}

At a constant temperature of $0^{\circ} \mathrm{C}$, GPT of appendicularians in the NEW averaged $74 \pm 23 \mathrm{~min}( \pm \mathrm{SD}, \mathrm{n}=$ 21 ), with a range of 40 to $125 \mathrm{~min}$. GPT was statistically independent of body size over the wide spatial and temporal scales of the NEW (Fig. 7A). Faecal pellet production rate (FPPR) had a mean of $41 \pm 15$ faecal pellets $\mathrm{d}^{-1}( \pm \mathrm{SD}, \mathrm{n}=21)$, ranging from 19 to 76 faecal pellets $d^{-1}$. FPPR also was statistically independent of body size (Fig. 7B). Since GPT in Oikopleura vanhoeffeni is essentially constant over a wide range of food concentrations (Bochdansky et al. 1998) and TL (Fig. 7a), ingestion rate can be directly calculated from GCC by,

$$
\mathrm{IR}=(\mathrm{GCC} / \mathrm{GPT}) k
$$


where IR = ingestion rate (ng total chlorophyll animal ${ }^{-1}$ $\left.\mathrm{d}^{-1}\right), \mathrm{GCC}=$ gut chlorophyll content $\left(\right.$ ng animal $\left.{ }^{-1}\right), \mathrm{GPT}=$ gut passage time (d) and $k=$ a correction factor to account for that portion of ingested chlorophyll which is converted either to phaeopigments or to non-fluorescent products, both of which are lost to our analytical technique (see 'Methods'). $k$ could not be determined during the present study. However, experiments conducted in Newfoundland, with the same species and at the same water temperatures as in the NEW, suggest that chlorophyll conversion efficiency is $79 \% \quad 195 \%$ CL of 76 to $83 \%$ ), indicating that $21 \%$ of ingested chlorophyll remains intact and undegraded during gut passage (Bochdansky et al. 1998). Thus, a value for $k$ of $4.76(1 \div$ 0.21 ) is a reasonable approximation over a wide range of food concentrations. Therefore, in the present calculations, we used a GPT of $1.23 \mathrm{~h}$ (i.e., $0.051 \mathrm{~d}$ ) and a $k$ of 4.76. We assumed that the value of $k$ does not vary with food concentration or food type (see 'Discussion').

Oikopleurid appendicularians in the NEW had a mean herbivorous ingestion rate of $379 \mathrm{ng} \mathrm{chl}$ ind.- ${ }^{-1}$ $\mathrm{d}^{-1}$, with quartiles of 112 to $441 \mathrm{ng}$ chl ind. ${ }^{-1} \mathrm{~d}^{-1}$. Assuming a C:chl a ratio of 60 (Booth \& Smith 1997), the mean daily ingestion rate of phytoplankton carbon was $23 \mu \mathrm{g} \mathrm{C}$ ind.$^{-1} \mathrm{~d}^{-1}$. Dividing this mean daily ingestion rate by the carbon mass of an appendicularian of mean size, calculated according to the equation of Deibel (1986), gives a mean, herbivorous daily ration of appendicularians in the NEW of $117 \%$ body carbon $\mathrm{d}^{-1}$.

\section{A generalized equation for predicting individual ingestion rates}

Because the ingestion rates in the previous section have been calculated from the original, raw GCC data, their allometric structure is the same as that shown in Fig. 2. In fact, we can combine Eq. (3) with Eq. (4) to derive an allometric equation describing the relationship between the ingestion rate of chlorophyll (IR, ng chl ind. ${ }^{-1} \mathrm{~d}^{-1}$ ) and the body size of appendicularians $(\mathrm{TL}, \mathrm{mm})$ in the NEW,

$$
\mathrm{IR}=2.5 \mathrm{BL}: \mathrm{BT}^{-0.41} \mathrm{TL}^{2.14}
$$

This ingestion rate can be converted to units of $\mathrm{ng} \mathrm{C}$ ind. ${ }^{-1} \mathrm{~d}^{-1}$ by multiplying by a $\mathrm{C}$ : chl ratio of 60 .

\section{DISCUSSION}

\section{Comparison of new method to published values}

In this paper, we report the first shipboard feeding measurements using net-collected appendicularians of which we know. Achieving these experiments has allowed us to examine ingestion rates in relation to several abiotic and biotic environmental conditions. The gut pigment technique is especially suited for the study of arctic oikopleurid appendicularians, because of the absence of diel feeding rhythms (Fig. 3 ; see also Redden 1994), the wide size range of ingested particles (Urban et al. 1992) and the lack of particle selection by the mucous filters within this range (Deibel \& Lee 1992, Bochdansky et al. 1998). Furthermore, Oikopleura vanhoeffeni is a relatively large appendicularian, allowing for the pigment analysis of individual guts.

Since the ingestion rates we report are based on the amount of phytoplankton pigment present in the guts of the appendicularians, they are true measures of the quantity of autotrophic particles removed from suspension that were actually consumed by the appendicularians. Therefore, no correction for the quantity of particles removed from suspension but remaining stuck to the mucous filters of the house is necessary (Gorsky 1980). This 'correction factor' has needed to be applied throughout the appendicularian feeding literature, as almost all publications have been based on determination of the disappearance of cells or particles from suspension in the water surrounding feeding appendicularians.

Although there are no previously published, herbivorous ingestion rate studies with which we can compare the present data, Bochdansky et al. (1998) and Bochdansky \& Deibel (1999a) have recently completed a systematic study of the clearance rates of Oikopleura vanhoeffeni using a suite of techniques, including particle removal determined using a Coulter Counter, video estimates of water flow rate and the quantity of gut pigment and GPT. These rates were then compared to 2 published studies of $O$. vanhoeffeni conducted in situ, one using radio-labeled algae (Knoechel \& Steel-Flynn 1989) and one using the uptake of fluorescent plastic beads (Deibel 1988). When corrected for loss using the same chlorophyll conversion efficiency we have used (i.e. $79 \%$ over all food concentrations), the clearance rates based on gut pigments were within a factor of 2 of those determined by Knoechel \& Steel-Flynn (1989) and Deibel (1988). Most importantly, the rates from all 3 studies were not significantly different from one another (Bochdansky \& Deibel 1999a). Although the chlorophyll conversion efficiency of $O$. vanhoeffeni did increase with decreasing gut fullness (Bochdansky et al. 1998), application of a variable conversion efficiency to the determination of clearance rates did not result in a statistically significant change in comparison with the constant conversion factor of $79 \%$ (Bochdansky et al. 1998). Therefore, we elected to use the simplest approach here, with a constant conversion efficiency of $79 \%$. We have assumed also that this conversion efficiency deter- 
mined for $O$. vanhoeffeni feeding on diatoms applies to the mixed prey community encountered in the field. This assumption is necessary because of the absence of any published or unpublished information on chlorophyll conversion during gut passage of non-diatom prey, due in part to the lack of a comparative technique to the sensitive ${ }^{68} \mathrm{Ge}$ ratio approach for diatoms. At least some of the gut contents of $O$. vanhoeffeni are diatoms (Urban et al. 1992, Acuña et al. 1996, J. L. Acuña, D. Deibel, P. Saunders, B. Booth \& E. Hatfield unpubl.) justifying our assumption for this first-order attempt at estimating in situ ingestion rates of $O$. vanhoeffeni. These estimates will be improved once chlorophyll conversion efficiencies for mixed populations of naturally occurring prey are determined.

\section{Bloom versus non-bloom feeding dynamics}

Appendicularian GCC and chlorophyll ingestion rates were highly variable over the space and time scale of our study. We recognized 2 separate domains of available food particles in the NEW, which we have called non-bloom and bloom stations. Below $0.8 \mathrm{mg}$ chl $a \mathrm{~m}^{-3}$ (i.e. the vertically averaged concentration over the upper $50 \mathrm{~m}$ at non-bloom stations) GCC was variable, and reached its highest values, while above $0.8 \mathrm{mg} \mathrm{chl} \mathrm{a} \mathrm{m}^{-3}$ (i.e. at bloom stations) GCC was low and relatively constant (Fig. 4). All of our non-bloom stations fall within regime 5 of Pesant et al. (1996), which is a biogeographically defined group of stations in which the production and biomass of phytoplankton is dominated by smail cells $<5 \mu \mathrm{m}$ in diameter. Although this size of particle is below the threshold for effective retention of most copepod species, it is well within the capability of Oikopleura vanhoeffeni to retain this particle size with $100 \%$ efficiency (Acuña et al. 1996). Thus, it is not surprising that appendicularians in the NEW have maximum gut fullness at the nondiatom-bloom stations (Fig. 4). This conclusion is consistent with predictions from a theoretical, fluid mechanical model of particle selection by $O$. vanhoeffeni, which postulated that $71 \%$ of the total ration of carbon in the NEW should come from particles $<20 \mu \mathrm{m}$ in diameter (Acuña et al. 1996)

What are likely mechanisms for the inhibition of ingestion at diatom bloom stations? Oikopleura vanhoeffeni and $O$. labradoriensis have mucous pre-filters on the outside of their houses that screen the inflowing water by trapping large and spiny particles (Deibel 1986). The pore width of these filters ranges from $40 \mu \mathrm{m}$ for juvenile $O$. vanhoeffeni to $140 \mu \mathrm{m}$ for adults (Deibel 1986). Thus, these filters could become clogged by large centric diatoms or by tabular chains of pennate diatoms, leading to decreasing ingestion rates and gut fullness. We have found observational support for the hypothesis that the herbivorous ingestion rate of appendicularians is controlled in part by the relative abundance of large particles (Fig. 6). This confirms over a wide spatial and temporal scale the in situ observations of Knoechel \& Steel-Flynn (1989), who found an inverse relationship between the clearance rate of $O$. vanhoeffeni and the concentration of large particles in coastal Newfoundland waters.

Since Cushing (1989) first proposed copepods as the dominant mesozooplankton grazers in classical, nitrate-driven, pelagic food chains, there has been a growing consensus that appendicularians dominate mesozooplankton grazing in regenerative, microbial loop systems (Deibel 1998). This paradigm has been based on the perception that appendicularians have evolved towards the concentration and capture of very small particles (Flood et al. 1992). This concept was challenged by the discovery of relatively large diatoms in faecal pellets of Oikopleura vanhoeffeni (Urban et al. 1992,1993), perhaps due to the large body size of $O$. vanhoeffeni and the large pore size of the inlet filters. However, the qualitative study by Urban et al. (1992, 1993 ) is not directly comparable to the present quantitative results. Urban et al. $(1992,1993)$ report simply on the presence of undigested phytoplankton remains in the faecal pellets as determined using electron microscopy, not on the absolute abundance of phytoplankton mass in the pellets nor on the relative abundance of diatoms versus smaller phytoplankton. Thus, Urban et al. $(1992,1993)$ did not collect data from which it is possible to determine the ingestion rate of diatoms. Although we cannot determine the relative ingestion rate of diatoms versus smaller cells from our gut chlorophyll measurements, the inverse relationship between ingestion rate and the relative abundance of phytoplankton larger than $5 \mu \mathrm{m}$ (Fig. 6) suggests that large particles not only form a small fraction of the biomass of consumed phytoplankton (see also Acuña et al. 1996) but also have a deleterious effect on ingestion rates.

\section{Estimation of ingestion rates}

Another important goal of this work was to derive a simple predictive model for the individual ingestion rates of appendicularians in the NEW. This task has been simplified by the absence of diel feeding rythms in arctic oikopleurid appendicularians (Fig. 3), which would have complicated the sampling design and data analysis (Head 1986) and would require including time of day as an additional independent variable. The task was also simplified by the low variability of GPT, and the stability of GPT over a wide range of body sizes 
(Fig. 7), food quantity and food quality. This result has been confirmed in laboratory studies of Oikopleura vanhoeffeni by Bochdansky et al. (1998). Thus, we can use a single value for GPT to estimate ingestion rates of appendicularians in the NEW.

In building the predictive equations, we have tried to achieve simplicity, and to give our equations not only an empirical, but also a functional basis. We have used body size and the relative concentration of large particles as predictor variables in an equation which can be used to estimate individual ingestion rate at any of the stations in the NEW (Eq. 5).

There is a considerable amount of variance unexplained by the model (ca. 50\%). One possibility is that this residual variance is due to our lack of information on the small-scale concordance of appendicularians and their prey. We believe this is unlikely however, since a similar magnitude of unexplained variance is shared by field studies of appendicularians using tracer particles (Alldredge 1981, Deibel 1988, Knoechel \& Steel-Flynn 1989), and even by experimental studies under highly controlled conditions and a unialgal diet in the laboratory $\left(r^{2}=24 \%\right.$ for log clearance rate versus $\log$ body size, Bochdansky \& Deibel 1999a, J. L. Acuña $\& M$. Kiefer unpubl.). This is very close to the variation of GCC explained by body size in nature, of $29 \%$ (see legend for Fig. 2). Thus, even when there is no small scale variation in the available chlorophyll concentration in laboratory experiments, there is high residual variation in feeding rates, similar to the residual variation in the field. This suggests that food patchiness is not responsible for the residual gut chlorophyll variation in the field. In addition, the clearance rate of a single individual can vary markedly over time due to the age and degree of clogging of the filters of the house, with a $70 \%$ reduction in clearance rate of an old versus a new house (Bochdansky \& Deibel 1999b). This 3 -fold range in feeding rate within a single individual depending upon the age of its filtration apparatus is greater than the 2 -fold range among various techniques for determining feeding rate (see above) and suggests that much of the residual variance observed in the field is real and due to recent feeding history.

Thus, we are confident that Eq. (5) gives a biologically meaningful, average prediction of feeding by appendicularians which can be extrapolated over the surface of the polynya. Moreover, there is a clear functional basis for the application of this equation, which is that the ingestion rate of appendicularians in the NEW clearly depends upon both body size (Fig. 2) and the relative abundance of large particles (Table 2, Fig. 6) which are known to clog the inlet filters and retard ingestion rates (Knoechel \& Steel-Flynn 1989). There is also a clear ecological basis for application of this equation, because all of the stations in the NEW have been divided into 3 biogeographic provinces (2 bloom and 1 non-bloom) based on the relative concentration of large phytoplankton cells (Pesant et al. 1996). According to Pesant et al. (1996) there are fundamental differences in trophic structure and ecosystem dynamics between diatom bloom stations, which correspond to export systems, and non-bloom stations, which correspond to regenerative systems (Pesant et al. 1996). Here we have shown that these contrasting ecosystem structures have profound implications on the trophic ecophysiology of appendicularian consumers.

Acknowledgements. We are greatly indebted to Ian Wegner for his help and stimulus during the cruise, to Hans-Jürgen Hirche for his plankton tows and support throughout the project and to Stephan Pesant and Louis Legendre for their chlorophyll data. During the writing phase, J.L.A. benefited from thoughtful discussions with Ricardo Anadón and statistical advice from Rosa Menéndez, Rosa Viejo, Marcos Méndez, Francisco Arenas and José Ramón Obeso. We also wish to thank our colleagues Torkeil Nielsen and P.-K. Bjornsen for opening so many doors for us. We could not have done this work without their generous assistance.

\section{LITERATURE CITED}

Acuña JL, Deibel D, Sooley S (1994) A simple device to transfer large and delicate planktonic organisms. Limnol Oceanogr 39:2001-2003

Acuña JL, Deibel D, Morris CC (1996) Particle capture mechanism of the pelagic tunicate Oikopleura vanhoeffeni. Limnol Oceanogr 41:1800-1814

Alldredge AL (1981) The impact of appendicularian grazing on natural food concentrations in situ. Limnol Oceanogr 26:247-257

Armitage P, Berry G (1987) Statistical methods in medical research. Blackwell Scientific Publications, Oxford

Ashjian CJ, Smith SL, Lane PVZ (1995) The Northeast Water Polynya during summer 1992: distribution and aspects of secondary production of copepods. J Geophys Res 100(C3): $4371-4388$

Ashjian C, Smith S, Bignami F, Hopkins T, Lane P (1997) Distribution of zooplankton in the Northeast Water Polynya during summer 1992. J Mar Syst 10:279-298

Bochdansky AB, Deibel D (1999a) Measurement of in situ clearance rates of Oikopleura vanhoeffeni (Appendicularia, Tunicata) from tail beat frequency, time spent feeding and individual body size. Mar Biol 133:37-44

Bochdansky AB, Deibel D (1999b) Functional feeding response and behavioral ecology of Oikopleura vanhoeffeni (Appendicularia, Tunicata). J Exp Mar Biol Ecol 233:181-211

Bochdansky AB, Deibel D. Hatfield EA (1998) Chorophyll a conversion and gut passage time for the pelagic tunicate Oikopleura vanhoeffeni (Appendicularia). J Plankton Res 20(11):2179-2197

Booth BC, Smith WO (1997) Autotrophic flagellates and diatoms in the Northeast Water Polynya, Greenland: summer 1993. J Mar Syst 10:241-261

Buchanan RA, Browne SAM (1981) Zooplankton of the Labrador Coast and shelf during summer 1979. Consultant's Report for Petro-Canada Explorations Ltd, LGL Limited, St. John's

Buck KR, Newton J (1995) Fecal pellet flux in Dabob Bay dur- 
ing a diatom bloom: contribution of microzooplankton. Limnol Oceanogr 40:306-315

Budéus G, Schneider W (1995) On the hydrography of the Northeast Water Polynya. J Geophys Res 100(C3):4287-4299

Cushing DH (1989) A difference in structure between ecosystems in strongly stratified waters and in those that are only weakly stratified. J Plankton Res 11(1):1-13

Deibel D (1986) Feeding mechanism and house of the appendicularian Oikopleura vanhoeffeni. Mar Biol 93:429-436

Deibel D (1988) Filter feeding by Oikopleura vanhoeffeni grazing impact on suspended particles in cold ocean waters. Mar Biol 99:177-186

Deibel D (1998) Feeding and metabolism of Appendicularia. In: Bone $Q$ (ed) The biology of pelagic tunicates. Oxford University Press, Oxford, p 139-150

Deibel D, Lee SH (1992) Retention efficiency of sub-micrometer particles by the pharyngeal filter of the pelagic tunicate Oikopleura vanhoeffeni. Mar Ecol Prog Ser 81:25-30

Deibel D, Turner JT (1985) Zooplankton feeding ecology: contents of fecal pellets of the appendicularian Oikopleura vanhoeffeni. Mar Ecol Prog Ser 27:67-78

Flood PR, Deibel D, Morris CC (1992) Filtration of colloidal melanin from seawater by planktonic tunicates. Nature 355:630-632

Gorsky G (1980) Optimisation des cultures d'Appendiculaires. Approche du métabolisme de $O$. dioica. PhD thesis, L'Universite Pierre et Marie Curie, Paris VI

Grainger EH (1965) Zooplankton from the Arctic Ocean and adjacent Canadian waters. J Fish Res Board Can 22 $543-564$

Head EJH (1986) Estimation of Arctic copepod grazing rates in vivo and comparison with in-vitro methods. Mar Biol 92 $371-379$

Hirche HJ, Kattner G (1994) The 1993 Northeast Water expedition scientific cruise report of RV 'Polarstern' Arctic cruises ARK IX/2 and 3, USCG 'Polar Sea' cruise NEWP and the NEWLand expedition. Alfred-Wegener-Institut für Polar- und Meeresforschung, Bremerhaven

Jansa J (1977) Estudio preliminar del contenido en pigmentos fotosintéticos en el tubo digestivo de apendicularias y salpas. Bol Inst Esp Oceanogr 228:7-29

Knoechel R, Steel-Flynn D (1989) Clearance rates of Oikopleura in cold coastal Newfoundland waters: a predictive model and its trophodynamic implications. Mar Ecol Prog Ser 53:257-266

Landry MR, Lorenzen CJ, Peterson WK (1994a) Mesozooplankton grazing in the Southern California Bight. II. Grazing impact and particulate flux. Mar Ecol Prog Ser 115:73-85

Landry MR, Peterson WK, Fagerness VL (1994b) Mesozooplankton grazing in the Southern California Bight. I. Population abundances and gut pigment contents. Mar Ecol Prog Ser 115:55-71

Mackas D, Bohrer R (1976) Fluorescence analysis of zoo-

Editorial responsibility: Thomas Kiorboe /Contributing Editor), Charlottenlund, Denmark plankton gut contents and an investigation of diel feeding patterns. J Exp Mar Biol Ecol 25:77-85

Madin LP, Cetta CM (1984) The use of gut fluorescence to estimate grazing by oceanic salps. J Plankton Res 6 : $475-492$

Madin LP, Kremer P (1995) Determination of the filter-feeding rates of salps (Tunicata, Thaliacea). ICES J Mar Sci 52: 583-595

Madin LP, Purcell JE (1992) Feeding, metabolism, and growth of Cyclosalpa bakeri in the subarctic Pacific. Limnol Oceanogr 37(6):1236-1251

Minne) PJ, Bignami F, Böhm E, Budéus G, Galbraith PS, Gudmandsen $P$, Hopkins TS, Ingram RG, Johnson MA, Niebauer HJ, Ramseier RO, Schneider W (1997) A summary of the formation and seasonal progression of the Northeast Water Polynya. J Mar Syst 10:79-85

Pesant S, Legendre L, Gosselin $M$, Smith REH, Kattner G, Ramseier RO (1996) Size-differential regimes of phytoplankton production in the Northeast Water Polynya $\left(77^{\circ}-81^{\circ} N\right)$. Mar Ecol Prog Ser 142:75-86

Redden AM (1994) Grazer-mediated chloropigment degradation and the vertical flux of spring bloom production in Conception Bay, Newfoundland. PhD thesis, Dept of Biology, Memorial University of Newfoundland, St. John's

Reeve MR (1981) Large cod-end reservoirs as an aid to the live collection of delicate zooplankton. Limnol Oceanogr 26:577-580

Schneider W, Budéus G (1995) On the generation of the Northeast Water Polynya. J Geophys Res 100(C3):4269-4286

Schneider W, Budéus G (1997) Summary of the Northeast Water Polynya formation and development (Greenland Sea). J Mar Syst 10:107-122

Shiga N (1976) Maturity stages and relative growth of Oikopleura Jabradoriensis Lohmann (Tunicata, Appendicularia). Bull Plankton Soc Jpn 23:81-95

Smith SD, Muench RD, Pease CH (1990) Polynyas and leads an overview of physical processes and environment J Geophys Res 95 (C6):9461-9479

Stirling I (1980) The biological importance of polynyas in the Canadian Arctic. Arctic 33:303-315

Udvardy MDF (1954) Distribution of appendicularians in relation to the Strait of Belle Isle. J Fish Res Bd Can 11. $431-453$

Underwood AJ (1997) Experiments in ecology. Their logical design and interpretation using analysis of variance. Cambridge University Press, Cambridge

Urban JL, McKenzie CH, Deibel D (1992) Seasonal differences in the content of Oikopleura vanhoeffeni and Calanus finmarchicus faecal pellets: illustrations of zooplankton food web shifts in coastal Newfoundland waters. Mar Ecol Prog Ser 84:255-264

Urban JL, McKenzie CH, Deibel D (1993) Nanoplankton found in fecal pellets of macrozooplankton in coastal Newfoundland waters. Bot Mar 36:267-281

Submitted: April 16, 1998, Accepted: January 7, 1999

Proofs received from author(s): August 13, 1999 